\title{
A construção de competências coletivas na dinâmica das rotinas orçamentárias
}

\author{
SAMANTHA LUIZA de SOUZA BROMAN ${ }^{1}$ \\ ROBERTO LIMA RUAS ${ }^{2}$ \\ SANDRA REGINA DA ROCHA-PINTO ${ }^{1}$ \\ 1 PontifíCIA UnIVERSIDADE CATÓlICA dO RIO DE JANEIRO (IAG/PUC- RIO), RIO DE JANEIRO - RJ, BRASIL \\ 2 UNIVERSIDAde NoVe de JULHo (PPGA/UNINOVE), SÃo PAULO - SP, BRASIL
}

\begin{abstract}
Resumo
A crescente difusão de configurações coletivas de trabalho no atual ambiente organizacional não tem apresentado contrapartida na produção científica sobre o tema (BOREHAM, 2011). Paradoxalmente, porém, alguns campos do debate sobre organizações destacam o papel dos coletivos de trabalho, como é o caso da literatura sobre Rotinas Organizacionais - RO - (NELSON e WINTER, 2005; PENTLAND e FELDMAN, 2005). A questão que mobiliza esta investigação explora a relação entre esses dois temas: a dinâmica das rotinas orçamentárias corporativas pode constituir um espaço adequado para a formação e o desenvolvimento de competências coletivas? O objetivo é examinar a elaboração de orçamentos corporativos, com base na abordagem de rotina organizacional, a fim de identificar evidências de coletivos de trabalho e da formação de atributos e competências coletivas. Essas respostas transitam por uma investigação qualitativa e fenomenográfica que apontou quatro categorias descritivas da configuração coletiva do trabalho: Comprometimento com a Entrega, Reconfiguração das Rotinas, Disponibilização Compartilhada e Construção de Redes de Relacionamento. De entre as contribuições da pesquisa, destaque para: o potencial da teoria das RO como referência a análise de processos corporativos; identificação de processos capazes de contribuir na gestão de coletivos de trabalho; e o emprego do método fenomenográfico como alternativa para apropriar fenômenos organizacionais de natureza pouco tangíveis.
\end{abstract}

Palavras-chave: Rotinas organizacionais. Competências coletivas. Dinâmica das rotinas. Fenomenografia.

\section{The construction of collective competencies in the dynamics of budgetary routines}

\begin{abstract}
The growing diffusion of collective work configurations in the current organizational environment has remained largely overlooked in the scientific body of work on the theme (BOREHAM, 2011). Paradoxically, however, certain currents in the debate about organizations highlight the role of collective work, as is the case with the literature on organizational routines (NELSON and WINTER, 2005; PENTLAND and FELDMAN, 2005). The question that motivates this investigation explores the relationship between those two themes: can the dynamics of corporate budgeting constitute an adequate space for the formation and development of collective competences? The objective of this question is an inquiry into the design of corporate budgets, from an organizational-routine approach, to identify evidence of teamwork and the formation of collective competences and attributes. The responses transit through a qualitative and phenomenographic investigation that pointed to four descriptive categories of collective work: commitment to deliver, reconfiguration of routines, shared availability, and building relationship networks. The contributions of the research include the potential of the organizational routines theory as a reference for the analysis of corporate processes, the identification of processes capable of contributing to the management of workgroups, and the use of the phenomenographic method as an alternative to frame somewhat intangible organizational phenomena.
\end{abstract}

Keywords: Organizational routines. Collective competencies. Dynamic routines. Phenomenography.

\section{La construcción de competencias colectivas en la dinámica de las rutinas presupuestarias}

\section{Resumen}

La creciente difusión de configuraciones colectivas de trabajo en el actual ambiente organizativo no ha presentado contrapartida en la producción científica acerca del tema (BOREHAN, 2011). Paradójicamente, sin embargo, algunos ámbitos del debate sobre las organizaciones subrayan el papel de los colectivos de trabajo, como es el caso de la literatura sobre Rutinas Organizativas (Nelson y Winter, 2005; PENTLAND y FELDMAN, 2005). La cuestión que motiva esta investigación explora la relación entre esos dos temas: ¿la dinámica de rutinas presupuestarias corporativas puede constituirse en un espacio adecuado a la formación y el desarrollo de competencias colectivas? Su objetivo es analizar la elaboración de presupuestos corporativos, basado en el enfoque de la rutina organizativa, con el fin de identificar evidencias de colectivos de trabajo y de la formación de atributos y competencias colectivas. Esas respuestas pasan por una investigación cualitativa y fenomenográfica que ha señalado cuatro categorías descriptivas de la configuración colectiva del trabajo: Compromiso con la Entrega, Reconfiguración de Rutinas, Ofrecimiento compartido y Construcción de Redes de Relaciones. Entre los aportes de la investigación, es notable el potencial de la teoría de las RO, como referencia al análisis de procesos corporativos, identificación de procesos capaces de contribuir a la gestión de colectivos de trabajo y el empleo del método fenomenográfico como alternativa para la apropiación de fenómenos organizativos de naturaleza poco tangibles.

Palabras clave: Rutinas organizativas. Competencias colectivas. Dinámica de rutinas. Fenomenografía. 


\section{INTRODUÇÃO}

A crescente difusão de configurações coletivas de trabalho no ambiente organizacional, como resultado da apropriação da comunicação digital, de redes horizontais de informação e da necessidade de compartilhar conhecimentos e expertises em suas relações internas e externas (BOREHAM, 2011), não tem apresentado contrapartida na produção científica sobre o tema. Ao contrário, questões relevantes acerca dos coletivos de trabalho, como seus atributos e suas competências, por exemplo, permanecem ainda como um gap raramente tratado no debate acerca da gestão das organizações (MICHAUX, 2011; RETOUR e KROHMER, 2011; LOUFRANI-FEDIDA e MISSONIER, 2015; MACKE e CRESPI, 2016). Paradoxalmente, alguns campos da literatura sobre organizações revelam a presença destacada da configuração coletiva e destacam o papel dos coletivos de trabalho. Um desses campos é o que trata de Rotinas Organizacionais (RO).

No conceito de rotina organizacional, um dos fundamentos da Teoria Evolucionária (NELSON e WINTER, 2005), destacam-se os comportamentos organizacionais que se repetem, mas, sujeitos às relações com o ambiente externo à organização, acabam por incorporar mudanças importantes em suas configurações (NELSON e WINTER, 2005). Nessa abordagem, a dimensão coletiva das RO é elemento fundamental na consolidação das rotinas, na medida em que se sobrepõe e orienta as iniciativas individuais (NELSON e WINTER, 2005); também para Michaux (2011), assim como para Feldman e Pentland (2003), as RO têm origem nas experiências e práticas coletivas e entendem que as RO são estruturadas com base em rotinas coletivas e não individuais. Assim, a dinâmica das RO pode ser uma oportunidade para ampliar o conhecimento e o debate acerca dos coletivos de trabalho, especialmente seus atributos e competências. Em virtude disso, examinamos a produção de rotinas orçamentárias corporativas, qualificadas neste trabalho como uma das expressões de RO (NELSON e WINTER, 2005).

Rotinas orçamentárias são atividades integrantes do planejamento de curto prazo e do sistema de controle das organizações - budgeting - (MERCHANT, 1981, 1998), com propósitos de planejamento, coordenação e alocação de recursos da empresa, determinação de volumes operacionais e uma dimensão de monitoramento/controle (EKHOLM e WALLIN, 2011; KIHN, 2011). Embora regidas por procedimentos, cronogramas e objetivos previamente definidos, as rotinas orçamentárias enfrentam imprevistos e dificuldades próprias ao contexto organizacional - relações com as áreas internas, atrasos nos prazos de entrega das informações, mudanças nas normas, etc. Apesar desses contratempos, os grupos devem continuar atendendo os requisitos corporativos e, por isso, são necessários processos de adaptação, recomposição e ajustamento do comportamento individual e coletivo no interior desses grupos, modificando, certamente, as competências exigidas de pessoas e grupos, a fim de atingir os resultados esperados.

A questão da adaptação e ajustamento das RO é especificamente tratada por Feldman (2000) e Feldman e Pentland (2003) na forma da recursividade entre estabilidade e mudança, destacando, de um lado, os aspectos institucionais das rotinas (objetivos e metas, prescrição do sequenciamento de atividades, prazos pré-determinados etc.), o que é denominado aspecto ostensivo da rotina, e, de outro, os movimentos de flexibilização relacionados a mudanças internas e adequação de processos e cronogramas, introduzidas por aqueles que as realizam, o que compõe o aspecto performativo das rotinas (FELDMAN, 2000). A recursividade entre estabilidade e mudança nas RO tem sido revisitada (FELDMAN, PENTLAND, D’ADDERIO et al., 2016) e também irá pautar a análise das rotinas orçamentárias.

Por sua vez, o trabalho coletivo pode ser caracterizado genericamente como a realização conjunta de uma mesma atividade ou de um mesmo processo de trabalho, envolvendo vários indivíduos, em locais e períodos de tempo comuns ou mesmo diferentes, compreendendo interdependências entre as tarefas, ações coordenadas e a possibilidade de comunicações mediadas (LEPLAT, 2000; CAROLY e BARCELLINI, 2013). Para atender essas condições, o trabalho coletivo requer dos indivíduos que o compõem compartilhamento de objetivos, mediação dos recursos disponíveis e consciência das restrições presentes na sua realização (MICHAUX, 2011). A recorrência no tempo do trabalho coletivo resulta na formação de atributos e competências (RETOUR e KHROMER, 2011).

Assim, o elemento mobilizador desta investigação é a relação entre a dinâmica das RO e a configuração do trabalho coletivo, relação está presente em diferentes estudos teórico-empíricos (FELDMAN, 2003; NELSON e WINTER, 2005; PENTLAND e FELDMAN, 2005; MICHAUX, 2011; PARMIGIANI e HOWARD-GRENVILLE, 2011; ALBA e TSOUKAS, 2013). É dessa relação que se origina o pressuposto de que as RO podem constituir ambientes potencialmente apropriados à presença de coletivos de trabalho e é também nessa relação que se fundamenta a questão de pesquisa deste trabalho: a dinâmica das rotinas orçamentárias corporativas pode constituir um espaço adequado à formação e ao desenvolvimento de competências coletivas? A busca por respostas a esta questão passa por uma investigação com gestores e membros atuantes em rotinas 
orçamentárias corporativas, em diferentes organizações, a fim de identificar e analisar se é possível evidenciar a formação e o desenvolvimento de coletivos de trabalho nesses ambientes. Como resultado, a investigação pretende contribuir para reduzir o gap entre a produção de conhecimento sobre coletivos de trabalho e seus atributos e competências.

O recurso teórico para tratar desse fenômeno é o próprio conceito de Competência Coletiva (CC), visando acompanhar e analisar as principais formas mobilizadoras de atributos coletivos nas rotinas orçamentárias (RETOUR e KHROMER, 2011; MICHAUX, 2011; DEFÉLIX, LE BOULAIRE, MONTIES et al., 2014; LE BOTERF, 2014; MACKE e CRESPI, 2016; SILVA e RUAS, 2016), enquanto as rotinas orçamentárias, em si, são analisadas à luz da noção de RO (NELSON e WINTER, 2005; FELDMAN, 2000, 2003, 2016; PENTLAND e FELDMAN, 2005; PARMIGIANI e HOWARD-GRENVILLE, 2011).

A metodologia empregada na pesquisa combina duas etapas distintas: primeiro, com a finalidade de identificar suas concepções acerca das vivências com grupos de trabalho, foi realizada uma análise fenomenográfica de entrevistas com 17 gestores de grupos de trabalho, atuantes em rotinas orçamentárias em diversas empresas, especialmente sobre os processos de configurações coletivas nesse ambiente; segundo, foram verificados e analisados os resultados desta primeira etapa com 20 membros de grupos de trabalho que também atuavam, à época, em rotinas orçamentárias.

Dentre os principais resultados desta pesquisa, destaca-se a identificação de quatro categorias descritivas acerca da formação e desenvolvimento de CC em rotinas orçamentárias: a) comprometimento com a entrega; b) reconfiguração contínua das rotinas visando melhorias; c) disponibilização compartilhada à adaptação das rotinas e da estrutura; d) construção de redes de relacionamento com outras equipes atuando em rotinas diferentes, a fim de apropriar melhorias.

O trabalho está organizado em cinco seções, incluindo esta introdução. Na segunda, aborda-se o referencial teórico empregado nas análises dos resultados, na terceira trata-se da metodologia utilizada, na quarta expõem-se e analisam-se os resultados encontrados, na quinta tem-se as considerações finais.

\section{Competências Coletivas e o Desenvolvimento de Coletivos de Trabalho}

Os estudos sobre CC começaram a se difundir nos anos 1990 e suscitaram um interesse relativamente importante nas décadas seguintes. No entanto, sua exploração nos campos teórico e empírico ainda se encontra em estado de consolidação, o que é revelado pelas diferentes concepções que cercam esse tema, tanto no debate nacional, quanto internacional (BORENHAM, 2004; MICHAUX, 2011; RETOUR e KROHMER, 2011; ARNAUD e MILLS, 2012; RUAS, SILVA, BECKER et al. 2013; CAROLY e BARCELLINI, 2013; LOUFRANI-FEDIDA e MISSONIER, 2015; MACKE e CRESPI, 2016; SILVA e RUAS, 2016).

Para Silva (2012), tratar de competências de natureza coletiva exige tanto a compreensão em relação ao contexto em que os grupos de trabalho atuam, quanto à forma como interagem. Segundo Le Boterf (2003), as competências coletivas são construídas com base em uma articulação entre relações mútuas, o que exige competências individuais do tipo "saber cooperar" e "saber aprender", a fim de colocá-las à disposição da equipe e gerar cooperação e aprendizagem no coletivo. Esse mesmo autor acrescenta que a qualidade das interações e da cooperação pode levar a ganhos de produtividade. Por sua vez, Boreham (2004) aponta o senso de interdependência desenvolvido no grupo como elemento fundamental da CC para superar a cultura do individualismo.

Michaux (2011) contribui de forma importante ao defender que a apropriação do conceito de capital social, na perspectiva interna de um grupo de trabalho, pode explicar os resultados positivos de uma ação coletiva, bem como as eventuais melhorias no desempenho desse grupo. Assim, relacionamento, interação, cooperação, interdependência, aprendizagem coletiva seriam alguns dos elementos componentes da perspectiva social de um grupo de trabalho e podem ser considerados fatores mobilizadores da formação de CC (MICHAUX, 2011). Retour e Krohmer (2011) exploram o ambiente interno de grupos de trabalho e identificam quatro atributos de natureza coletiva capazes de mobilizar competências coletivas, os quais são assim denominados por esses autores: referencial comum - elemento estruturador de ação coletiva para uma atividade a ser realizada; linguagem compartilhada, atributo capaz de abreviar a comunicação e, assim, agilizar muitas operações; memória coletiva, suporte para decisões presentes com base em aprendizados do passado; e, ainda, engajamento subjetivo, que se refere a uma mobilização coletiva em direção a metas e objetivos.

A esse respeito, Ruas, Silva, Becker et al. (2013) descrevem resultados de uma pesquisa realizada em cinco empresas de grande porte, nas quais se observam a valorização dos processos de interação, cooperação e compartilhamento de conhecimentos e habilidades desenvolvidos no interior de diferentes grupos de projetos voltados à solução de problemas estratégicos e ao desenvolvimento de inovações. Uma contribuição importante desta pesquisa é a constatação de que, entre esses grupos de 
trabalho, aparecem diferentes estágios de desenvolvimento de um coletivo de trabalho: (a) existência de atividade coletiva; (b) institucionalização da atividade coletiva; (c) formação de atributo de natureza coletiva na atividade; (d) constatação da existência de CC capaz de melhorar desempenho do coletivo de trabalho.

Já Silva e Ruas (2016), em um estudo voltado à identificação e análise de CC em práticas de gestão de pessoas em empresa do setor financeiro, observam que tratar práticas de gestão na forma de rotinas organizacionais constitui um procedimento facilitador da análise das relações internas entre os membros dos grupos que realizam essas rotinas. 0 emprego desse procedimento permitiu aos autores identificar dois tipos de CC relacionadas a rotinas de gestão de pessoas, bem como os estágios de desenvolvimento de cada uma dessas competências.

Finalmente, Caroly e Barcellini (2013) argumentam que é preciso distinguir um grupo de trabalho de um coletivo de trabalho. Segundo essas autoras, o coletivo de trabalho é uma configuração que apresenta um desempenho coletivo superior ao grupo de trabalho convencional. Esse desempenho superior é em geral resultante do desenvolvimento, num determinado grupo, de competências associadas a uma atuação do tipo coletiva, tais como: cooperação, compartilhamento, comunicação, confiança mútua, avaliação da relação com o objetivo do coletivo e outros (ARNOUD e FALZON, 2013). Evidentemente, além das competências próprias aos indivíduos do grupo, o desenvolvimento de CC depende de uma atuação continuada que gere amadurecimento das relações internas ao grupo. A construção das competências associadas à atuação coletiva é um dos temas centrais da abordagem de CCS (BORENHAM, 2004; MICHAUX, 2011; RETOUR e KROHMER, 2011; RUAS, SILVA, BECKER et al., 2013; MACKE e CRESPI, 2016; SILVA e RUAS, 2016).

\section{Rotinas organizacionais: considerações sobre sua dinâmica}

Embora os primeiros registros de estudos relacionados a rotinas e comportamentos organizacionais sejam atribuídos aos pioneiros trabalhos de March e Simon (1958) e Cyert e March (1963), a noção de RO foi consolidada por Nelson e Winter (1982), na perspectiva da Teoria Evolucionária, como forma de destacar os comportamentos organizacionais que se repetem no tempo. Segundo Nelson e Winter (2005), rotinas técnicas para a produção de bens, rotinas para identificar itens mais importantes no estoque, rotinas para identificar necessidades de investimentos em P\&D, estratégias para decidir sobre investimentos internacionais são considerados exemplos de RO. As rotinas orçamentárias coorporativas constituem um tipo de RO.

Uma das questões mais controversas no debate sobre o tema, e muito relevante nesta investigação, refere-se à dinâmica entre estabilidade e mudança nas $\mathrm{RO}$. Sendo a repetitividade elemento específico às rotinas, seria difícil pensar uma rotina sem repetição; no entanto, não há como não considerar os limites da repetitividade em ambientes instáveis e dinâmicos (NASCIMENTO, RUAS e SILVA, 2017). Segundo Parmigiani e Howard-Grenville (2011), na herança genética e seletiva, afirmada por Nelson e Winter (2005), as rotinas eram conceituadas como uma conjunção de regras simples, procedimentos padronizados e padrões de comportamento que auxiliavam na reação ao ambiente e na resolução de conflitos de uma forma mais eficiente (PARMIGIANI e HOWARD-GRENVILLE, 2011). Por isso, a visão de RO por Nelson e Winter (2005) é considerada um exemplo da perspectiva das capacidades, e constituiria uma visão excessivamente normativa (FELDMAN e PENTLAND, 2005; MICHAUX, 2011). Desse modo, uma contribuição decisiva sobre o que se pode denominar flexibilidade das RO advém dos trabalhos de Feldman (2000) e Feldman e Pentland (2003).

Feldman (2000) compreende as RO como processos vivos que podem ser modificados pela atuação dos agentes que as executam e vivenciam a relação entre os fluxos previstos nas RO e as dificuldades que se interpõem no dia a dia. Ou seja, se a rotina leva a um efeito diferente do esperado, os participantes devem alterá-la de forma a obter o resultado desejado (FELDMAN, 2000). Assim, se a responsabilidade sobre a rotina é atribuída a um grupo de indivíduos, as "ações" do grupo podem ser qualificadas como relacionais (FELDMAN, PENTLAND, D'ADDERIO et al., 2016). Com base nesta perspectiva, as RO são definidas por Feldman e Pentland (2003, p. 95) como "[...] padrões repetitivos e reconhecíveis de ações interdependentes realizadas por múltiplos atores".

Feldman, Pentland, D’Adderio et al. (2016) entendem que ao valorizar a atuação transformadora dos atores internos sobre as rotinas, observam que as mudanças em rotinas não dependem apenas da interveniência de fatores externos, mas são também sujeitas a mudanças geradas internamente a elas. A esse dinamismo ampliado, Feldman, Pentland, D’Adderio et al. (2016) denominam dynamic routines, conceito segundo o qual são considerados não apenas o que acontece "dentro" das rotinas, mas também a ecologia delas, ou seja, sua interdependência mútua.

Por isso, o referencial acerca das RO, especialmente em seus aspectos ostensivo e performativo, apresenta um grande potencial de contribuição para a análise da atuação dos diferentes grupos responsáveis pelas rotinas orçamentárias aqui examinadas. 


\section{Rotinas organizacionais como lócus para as configurações coletivas}

Na literatura sobre competências coletivas, Michaux (2011) posiciona as RO como o espaço onde se articulam as dimensões individuais, coletivas e organizacionais das competências corporativas. A autora considera que as rotinas são tácitas e têm origem em experiências e processos de aprendizagens coletivos ao longo do tempo, mediante práticas conjuntas (MICHAUX, 2011). Definir RO como resultado de aprendizagem coletiva pode se relacionar a um de seus princípios seminais: nas rotinas, o coletivo se sobrepõe aos interesses e às iniciativas individuais (NELSON e WINTER, 2005). Entretanto, segundo Feldman e Pentland (2003), a predominância do coletivo sobre o individual não evita os processos de flexibilização das rotinas, que podem ser alteradas ou preservadas; nem evita a necessidade de revisão e reconfiguração periódicas da distribuição e coordenação das ações entre os diversos atores, especialmente em momentos marcados por dificuldades e imprevistos (FELDMAN e PENTLAND, 2003; PARMIGIANI e HOWARD-GRENVILLE, 2011; FELDMAN, 2016). Feldman e Pentland (2003) ainda lembram que a RO é estruturada com base em rotinas coletivas e não individuais; assim, quando os "participantes múltiplos" das rotinas introduzem diferentes interpretações a seu respeito, tal diversidade é moderada por requisitos e condições institucionais, tais como objetivos, cronogramas e diretrizes corporativas.

Dessa maneira, a consolidação das rotinas passa necessariamente por uma articulação dinâmica e, muitas vezes, complexa, entre as perspectivas ostensiva (diretrizes institucionais) e performativa (adequações e reconfigurações) das RO. Nesse exercício, os grupos de trabalho, responsáveis pela condução das rotinas, tornam-se atores de um processo de aprendizagem coletiva. Um dos resultados desse processo é o desenvolvimento de atributos/competências de natureza coletiva, tais como comprometimento com os requisitos das rotinas, adaptação, compartilhamento, relacionamento e comunicação, confiança mútua, improvisação, visão sistêmica e outros (ARNOUD e FALZON, 2013). Finalmente, no que concerne ao desempenho dos grupos, cabe a consideração de que algumas correntes da literatura distinguem "grupo de trabalho" de "coletivo de trabalho" - este último trata-se de uma configuração avançada do primeiro, pois apresenta um desempenho coletivo superior, muitas vezes resultante da presença de atributos/competências de natureza coletiva (CAROLY e BARCELLINI, 2013).

Com base nas observações acima, examinou-se, nesta pesquisa, a formação de competências coletivas no lócus das RO.

\section{METODOLOGIA}

O presente trabalho é empírico, seu objetivo é o de contribuir com os estudos sobre a formação de competências coletivas em equipes (grupos de trabalho) e seu foco são as rotinas organizacionais orçamentárias em diversas empresas.

Em sua primeira etapa, o método empregado foi a fenomenografia, à luz das propostas teórico-metodológicas de Marton e Booth (1997); bem como foram abordados gerentes de grupos de trabalho em rotinas orçamentárias. Na segunda etapa buscou-se compreender, por meio de múltiplos casos, a visão da categoria de atores não contemplados na etapa anterior: os demais membros dos grupos de trabalho. Desse modo, a pesquisa de campo compreendeu duas etapas de campo, com 37 entrevistas ao todo, que foram realizadas em 24 empresas diferentes, cujos sujeitos são especificados no Quadro 1.

A abordagem teórico-metodológica da fenomenografia baseia-se em experiências qualitativamente variadas, vividas por diversos sujeitos, em relação a um determinado fenômeno. Adota-se a perspectiva de segunda-ordem, por meio da qual se busca tanto a visão dos sujeitos que vivenciam as experiências, quanto o significado a elas atribuído. Assim, com base no conjunto dos relatos das maneiras distintas sobre como os indivíduos percebem o fenômeno em suas práticas, identificam-se categorias representativas das concepções dos sujeitos; essas categorias/concepções representam partes constituintes do fenômeno estudado, revelando um mapa teórico da consciência coletiva (MARTON, 1981; MARTON e BOOTH, 1997; SANDBERG, 2000). A análise fenomenográfica também identifica as dimensões explicativas/aspectos críticos que caracterizam e esclarecem de que forma as categorias se distinguem. As categorias e as dimensões são apresentadas de forma sistematizada em um mapa de espaço de resultado, chamado de outcomespace - mapa de espaço de resultado - (COLLIER-REED e INGERMAN, 2013).

Dado que a fenomenografia preconiza que a amostra seja a mais variada possível (SANDBERG, 2000; AKERLIND, 2005), foram realizadas entrevistas individuais com gestores de grupos de trabalho atuantes em 17 empresas distintas. Esta etapa foi realizada no período de 11 de setembro a 16 de novembro de 2014 (Quadro1: parte 1). Aplicou-se um roteiro semiestruturado e as entrevistas duraram de 30 a 40 minutos. A esse respeito, observa-se que o conhecimento prévio sobre a base financeiroorçamentária que movimenta essas rotinas, tanto por parte da pesquisadora que realizou as entrevistas, como dos entrevistados, 
auxiliou na redução substancial do tempo empregado nas entrevistas. A análise das transcrições seguiu as recomendações da fenomenografia (MARTON e BOOTH, 1997; AKERLIND, 2005), especialmente a descontextualização dos sujeitos. Primeiramente, procedeu-se a uma leitura de todas as transcrições, observando-se as semelhanças mais significativas que se sobressaíram. Posteriormente, realizou-se uma leitura minuciosa de cada uma delas. Assim, as semelhanças identificadas propiciaram a seleção de trechos dos depoimentos (quotes) que evidenciaram as categorias identificadas, bem como auxiliaram na assimilação de dimensões que explicaram o contexto no qual ocorriam as rotinas.

A avaliação e os debates, inclusive em congresso, acerca dos principais resultados desta etapa revelou a necessidade de aprofundar a pesquisa, buscando também a visão de membros de grupos de trabalho atuantes na execução de rotinas orçamentárias, a fim de não limitar a pesquisa à opinião dos gestores. Assim, concebeu-se uma segunda etapa com um estudo de múltiplos casos (GHAURI, 2004).

Na escolha dos novos sujeitos evitaram-se grupos de trabalho nos quais atuavam os gestores entrevistados na primeira fase; o que envolveu 20 membros de outros grupos atuando na execução de rotinas orçamentárias, sendo 14 deles selecionados em 7 novas empresas. A segunda etapa de entrevistas pretendeu averiguar a presença de dificuldades para a consolidação dos coletivos de trabalho, como, por exemplo, conflitos na equipe. Assim, no período de 23 de março a 21 de julho de 2016, o primeiro outcomespace foi demonstrado e explicado aos 20 membros de equipes (Quadro 1: parte 2), juntamente com um novo roteiro semiestruturado. No roteiro dessas entrevistas, solicitava-se que os respondentes explicassem situações por eles vivenciadas que fossem relacionadas com o conteúdo do quadro.

A análise dos múltiplos casos da segunda fase ocorreu de forma similar à fenomenográfica, tendo sido acrescentada uma etapa de releitura, dedicada à análise da natureza dos novos achados (Figura 1).

A última fase da pesquisa constituiu-se da construção do Quadro de Resultados Consolidados (Figura 2), que tratou especificamente da sistematização dos resultados de análise. Assim, representa as principais questões acerca dos processos capazes de mobilizar a formação e o desenvolvimento de competências coletivas.

\section{Quadro 1}

\section{Sujeitos entrevistados}

\begin{tabular}{|c|c|c|c|c|c|}
\hline \multicolumn{3}{|c|}{ Parte 1: Primeira etapa da pesquisa } & \multicolumn{3}{|c|}{ Parte 2: Segunda etapa da pesquisa } \\
\hline \multicolumn{3}{|c|}{ Sujeitos entrevistados: Gestores de equipes } & \multicolumn{3}{|c|}{ Sujeitos entrevistados: Membros de equipes } \\
\hline Sujeito & Setor de Atividade & Gênero & Sujeito & Setor de Atividade & Gênero \\
\hline 1 & Farmacêutico-Cosmético & Masculino & 18 & Transporte Aéreo & Feminino \\
\hline 2 & Logística & Masculino & 19 & Óleo e Gás & Feminino \\
\hline 3 & Incorporadora & Feminino & 20 & Óleo e Gás & Feminino \\
\hline 4 & Farmacêutico-Cosmético & Masculino & 21 & Farmacêutico-Cosmético & Feminino \\
\hline 5 & Mineração & Masculino & 22 & Farmacêutico-Cosmético & Feminino \\
\hline 6 & Óleo e Gás & Feminino & 23 & Farmacêutico-Cosmético & Feminino \\
\hline 7 & Óleo e Gás & Feminino & 24 & Mineração & Feminino \\
\hline 8 & Farmacêutico-Cosmético & Masculino & 25 & Previdência & Feminino \\
\hline 9 & Telecomunicações & Masculino & 26 & Previdência & Feminino \\
\hline 10 & Telecomunicações & Masculino & 27 & Telecomunicações & Masculino \\
\hline 11 & Telecomunicações & Masculino & 28 & Seguros & Masculino \\
\hline 12 & Farmacêutico-Cosmético & Masculino & 29 & Alimentos e Bebidas & Masculino \\
\hline 13 & Alimentos e Bebidas & Feminino & 30 & Óleo e Gás & Masculino \\
\hline 14 & Óleo e Gás & Feminino & 31 & Óleo e Gás & Feminino \\
\hline 15 & Telecomunicações & Masculino & 32 & Telecomunicações & Feminino \\
\hline 16 & Farmacêutico-Cosmético & Feminino & 33 & Telecomunicações & Masculino \\
\hline \multirow[t]{4}{*}{17} & Financeira e Seguradora & Masculino & 34 & Telecomunicações & Masculino \\
\hline & & & 35 & Produção e Com. musical & Feminino \\
\hline & & & 36 & TV e Jornalismo & Masculino \\
\hline & & & 37 & Mineração & Feminino \\
\hline
\end{tabular}

Fonte: Elaborado pelos autores. 
Figura 1

Desenho da Pesquisa

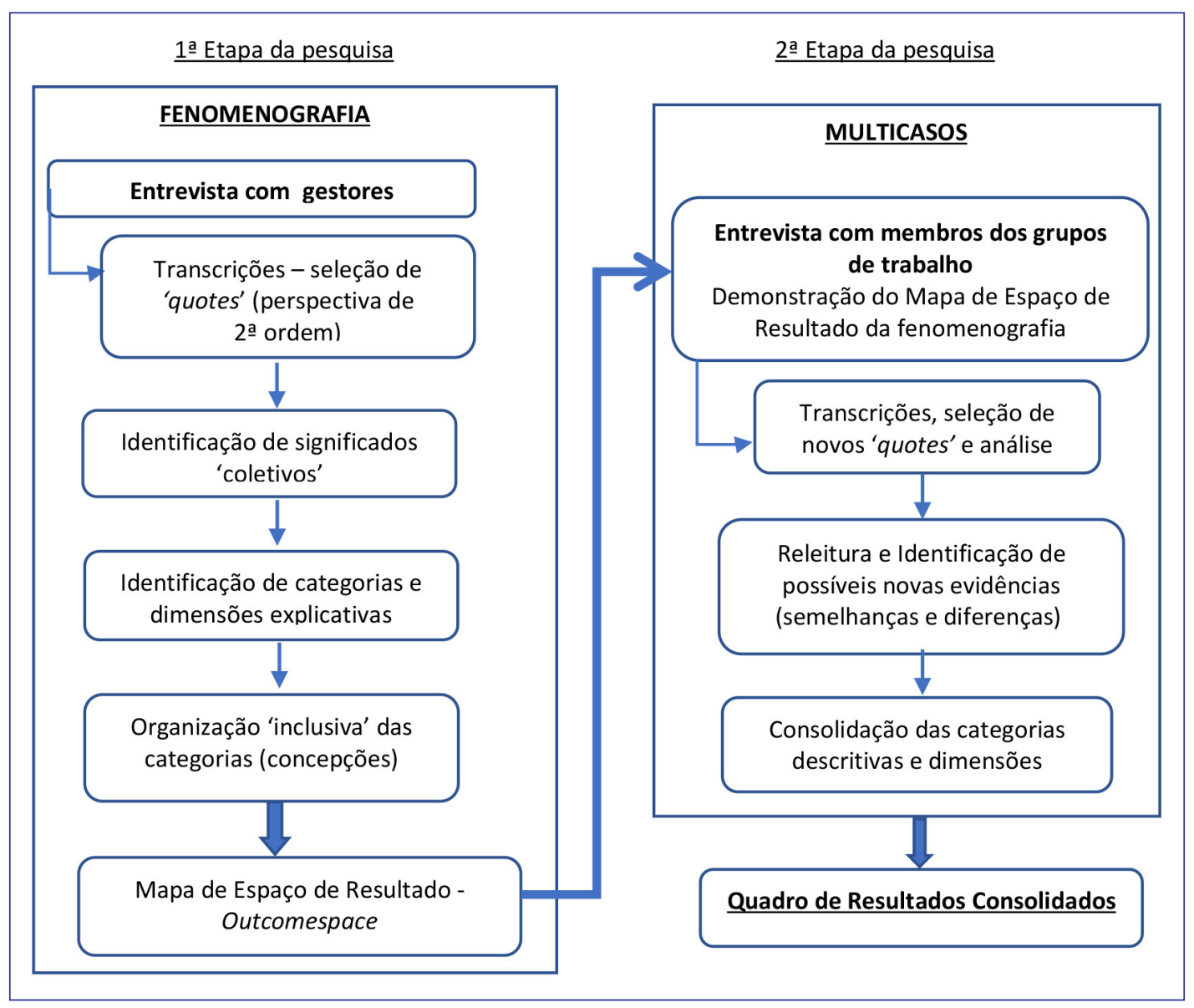

Fonte: Elaborada pelos autores.

\section{Principais Resultados e Contribuições}

A análise dos resultados apontou quatro categorias descritivas do fenômeno relacionado à formação de competências coletivas no ambiente das rotinas orçamentárias: a) comprometimento com a entrega; b) reconfiguração contínua das rotinas visando melhorias; c) disponibilização compartilhada entre membros do grupo para adaptação das rotinas e da estrutura; d) construção de redes de relacionamento com outros grupos atuando em outras rotinas, a fim de apropriar melhorias. Essas categorias descritivas sustentam-se por meio de dimensões explicativas que as diferenciam: i) a dinâmica formada pela relação entre os aspectos ostensivo e performativo das rotinas; ii) as perturbações na agenda de atividades das rotinas; iii) a natureza das relações internas no grupo de trabalho; e iv) o nível de autonomia desses grupos.

O Quadro de Resultados Consolidados - Figura 2 - apresenta tanto as categorias descritivas, como as dimensões explicativas. As categorias descritivas acerca do fenômeno de formação de competências coletivas no ambiente das rotinas orçamentárias encontram-se posicionadas nas colunas, enquanto as dimensões explicativas ocupam as linhas do Quadro. 
Figura 2

\section{Quadro de Resultados Consolidados}

\begin{tabular}{|c|c|c|c|c|}
\hline $\begin{array}{l}\text { Categorias } \\
\text { descritivas: }\end{array}$ & $\begin{array}{l}\text { Comprometimento } \\
\text { com a entrega }\end{array}$ & $\begin{array}{l}\text { Reconfiguração } \\
\text { das rotinas }\end{array}$ & $\begin{array}{l}\text { Disponibilização } \\
\text { compartilhada }\end{array}$ & $\begin{array}{l}\text { Construção de redes } \\
\text { de relacionamento }\end{array}$ \\
\hline $\begin{array}{l}\text { Resultado da } \\
\text { primeira etapa } \\
\text { da pesquisa } \\
\text { realizada com } \\
\text { os gestores: }\end{array}$ & $\begin{array}{l}\text { As equipes se empe- } \\
\text { nham uniformemente } \\
\text { no enfrentamento de } \\
\text { desafios e em esfor- } \\
\text { ços extras para que as } \\
\text { "entregas" do grupo } \\
\text { sejam cumpridas de } \\
\text { acordo com a rotina } \\
\text { ideal prevista nos calen- } \\
\text { dários orçamentários. } \\
\text { Cumprem no prazo. }\end{array}$ & \begin{tabular}{|c|} 
As equipes promovem \\
mudanças nas rotinas para \\
otimizar o trabalho e obter \\
melhorias de processo con- \\
tinuamente. Assim, emerge \\
das equipes a busca por \\
obter mais eficiência nas \\
rotinas.
\end{tabular} & $\begin{array}{c}\text { As equipes buscam estarem } \\
\text { aptas à adaptação a situações } \\
\text { adversas, para, assim se auto } \\
\text { organizarem conforme a situa- } \\
\text { ção (têm uma característica } \\
\text { líquida). } \\
\text { Realizam práticas coletivas } \\
\text { de redundâncias (rodízios, } \\
\text { backups, taskforce), que pos- } \\
\text { sibilitam que a categoria se } \\
\text { manifeste no senso compar- } \\
\text { tilhado de redistribuir as res- } \\
\text { ponsabilidades em sinergia. }\end{array}$ & $\begin{array}{l}\text { As equipes constroem redes de } \\
\text { relacionamento e buscam com- } \\
\text { preender o ponto de vista das } \\
\text { áreas adjacentes e/ou áreas } \\
\text { clientes. Logo, abrange não só a } \\
\text { própria equipe, como também } \\
\text { a organização. } \\
\text { As equipes demonstram auto- } \\
\text { nomia para se relacionar intra- } \\
\text { grupo e preocupam-se com a } \\
\text { exposição e o reconhecimento. }\end{array}$ \\
\hline $\begin{array}{l}\text { Resultado da } \\
\text { segunda etapa } \\
\text { da pesquisa } \\
\text { realizada com } \\
\text { os membros } \\
\text { de equipes: }\end{array}$ & $\begin{array}{l}\text { Em geral, as demandas } \\
\text { não são questionadas } \\
\text { nem recusadas, mesmo } \\
\text { quando imprevistas. } \\
\text { Isso ocorre em um } \\
\text { cenário no qual já con- } \\
\text { vivem com longas jor- } \\
\text { nadas e com a interde- } \\
\text { pendência com outras } \\
\text { áreas da empresa. }\end{array}$ & \begin{tabular}{|} 
Mudar e tornar as rotinas \\
mais eficientes é necessário, \\
bem como a internalizado \\
nas equipes. "Processos \\
construídos de baixo para \\
cima" [E30]. \\
Relatam diversas evidên- \\
cias sobre as melhorias das \\
rotinas ao longo dos últi- \\
mos anos, que propicia- \\
ram redução no excesso das \\
jornadas.
\end{tabular} & $\begin{array}{l}\text { Buscam evitar uma ruptura } \\
\text { da rotina nas situações de } \\
\text { urgência. } \\
\text { Colaboram entre si. } \\
\text { Além disso, apontam que a } \\
\text { oportunidade de aprendiza- } \\
\text { gem é motivacional. } \\
\text { Um relato de membro de } \\
\text { equipe apontou que seria pre- } \\
\text { ciso superar uma } \\
\text { "falta de confiança" na equipe } \\
\text { e uma competitividade interna } \\
\text { para iniciar a prática coletiva e } \\
\text { manifestar esta categoria. }\end{array}$ & $\begin{array}{l}\text { Os membros das equipes tam- } \\
\text { bém afirmam que são autôno- } \\
\text { mos para se relacionarem dire- } \\
\text { tamente com as outras áreas } \\
\text { (com diretores ou com seus } \\
\text { pontos de reciprocidade). } \\
\text { As reconfigurações das rotinas } \\
\text { ou modificações nos instru- } \\
\text { mentos são decididas em con- } \\
\text { junto com as outras áreas. }\end{array}$ \\
\hline $\begin{array}{l}\text { Dimensão } \\
\text { Explicativa: } \\
\text { Ajustamento } \\
\text { entre aspectos } \\
\text { performativo } \\
\text { e ostensivo }\end{array}$ & $\begin{array}{c}\text { As equipes cumprem } \\
\text { com as demandas (pre- } \\
\text { vistas ou imprevistas). E } \\
\text { esse comprometimento } \\
\text { é visto como resultado } \\
\text { da equipe e não de indi- } \\
\text { víduos isolados. } \\
\text { Os calendários assu- } \\
\text { mem um referencial } \\
\text { comum (ostensivo). }\end{array}$ & $\begin{array}{c}\text { As equipes repensam e } \\
\text { mudam as rotinas orçamen- } \\
\text { tárias, com foco nas tare- } \\
\text { fas, para torná-las mais efi- } \\
\text { cientes. Inclui uma visão de } \\
\text { reduzir esforços desneces- } \\
\text { sários e retrabalhos. }\end{array}$ & $\begin{array}{l}\text { As equipes atuam com foco } \\
\text { no compartilhamento e na } \\
\text { (re)distribuição das respon- } \\
\text { sabilidades para mudar ou } \\
\text { manter as rotinas orçamen- } \\
\text { tárias. São conscientes da } \\
\text { interdependência. } \\
\text { Os backups são importantes } \\
\text { para que não haja "donos" das } \\
\text { informações. }\end{array}$ & $\begin{array}{c}\text { As equipes mudam as rotinas } \\
\text { em prol da performance tendo } \\
\text { por base a premissa de que } \\
\text { devem ser validadas e/ou com- } \\
\text { binadas com as rotinas adja- } \\
\text { centes ou outras áreas. Inclui } \\
\text { uma visão das vantagens tam- } \\
\text { bém para as outras áreas. } \\
\text { Foi mencionado que precisam } \\
\text { compreender as informações } \\
\text { relacionadas com as outras } \\
\text { áreas. }\end{array}$ \\
\hline $\begin{array}{l}\text { Dimensão } \\
\text { Explicativa: } \\
\text { Agenda de } \\
\text { atividades }\end{array}$ & $\begin{array}{l}\text { Longas Jornadas. A } \\
\text { equipe é comprome- } \\
\text { tida e aceita as deman- } \\
\text { das fora do calendário, } \\
\text { elabora materiais adi- } \\
\text { cionais para reuniões } \\
\text { extraordinárias. } \\
\text { "Ficam para a pizza à } \\
\text { noite". } \\
\text { Comprometimento } \\
\text { coletivo. } \\
\text { Os membros das equi- } \\
\text { pes alegam que pos- } \\
\text { suem um horário flexí- } \\
\text { vel (informal). }\end{array}$ & \begin{tabular}{|c|} 
Longas Jornadas. A rea- \\
lidade é dinâmica, assim \\
como as empresas. As lon- \\
gas jornadas configuram a \\
principal motivação pela \\
qual as equipes buscam oti- \\
mizar as rotinas. \\
"Ficam para a pizza à noite" \\
Trechos trazem vivências \\
que confirmam redução \\
de excesso de jornada nos \\
ciclos orçamentários.
\end{tabular} & $\begin{array}{l}\text { Longas Jornadas e momen- } \\
\text { tos de quadro de funcioná- } \\
\text { rios reduzido motivaram as } \\
\text { equipes a se manterem flexí- } \\
\text { veis para auto organizarem-se } \\
\text { (líquidas). } \\
\text { "Ficam para a pizza à noite". } \\
\text { Esforços extras em períodos } \\
\text { de "pico" e as substituições } \\
\text { entre os membros das equi- } \\
\text { pes podem ser momentos de } \\
\text { aprendizagem. }\end{array}$ & $\begin{array}{c}\text { Como os prazos são restritos, } \\
\text { alegam que não há tempo de } \\
\text { os gestores acompanharem } \\
\text { suas ações e interações com as } \\
\text { outras áreas. } \\
\text { "Ficam para a pizza à noite". }\end{array}$ \\
\hline
\end{tabular}




\begin{tabular}{|c|c|c|c|c|}
\hline $\begin{array}{l}\text { Categorias } \\
\text { descritivas: }\end{array}$ & $\begin{array}{l}\text { Comprometimento } \\
\text { com a entrega }\end{array}$ & $\begin{array}{l}\text { Reconfiguração } \\
\text { das rotinas }\end{array}$ & $\begin{array}{l}\text { Disponibilização } \\
\text { compartilhada }\end{array}$ & $\begin{array}{l}\text { Construção de redes } \\
\text { de relacionamento }\end{array}$ \\
\hline $\begin{array}{l}\text { Dimensão } \\
\text { Explicativa: } \\
\text { Natureza das } \\
\text { Relações }\end{array}$ & Colaborativa & Colaborativa & $\begin{array}{c}\text { Colaborativa } \\
\text { Na 2a etapa surgiu o enten- } \\
\text { dimento de que a colabora- } \\
\text { ção pode ser deliberativa, } \\
\text { mas também pode ser perce- } \\
\text { bida como "algo necessário" } \\
\text { para alcançar os objetivos da } \\
\text { equipe. }\end{array}$ & $\begin{array}{c}\text { Colaborativa intragrupo e tam- } \\
\text { bém intergrupos. }\end{array}$ \\
\hline $\begin{array}{l}\text { Dimensão } \\
\text { Explicativa: } \\
\text { Autonomia }\end{array}$ & & $\begin{array}{l}\text { Existem traços de autono- } \\
\text { mia, pois as reconfigura- } \\
\text { ções nas rotinas surgem } \\
\text { de forma endógena, tendo } \\
\text { em vista que se percebe a } \\
\text { agência. } \\
\text { "Bottom up". }\end{array}$ & $\begin{array}{l}\text { Demonstra autonomia, prin- } \\
\text { cipalmente no que tange } \\
\text { aos interesses intragrupo de } \\
\text { compartilhar aprendizado e } \\
\text { descobertas. }\end{array}$ & $\begin{array}{c}\text { As equipes percebem-se autô- } \\
\text { nomas e relatam que atuam } \\
\text { com sua rede de relaciona- } \\
\text { mento de forma independente. } \\
\text { Pode ser necessário desen- } \\
\text { volver a autonomia dos novos } \\
\text { integrantes. }\end{array}$ \\
\hline
\end{tabular}

Fonte: Elaborada pelos autores.

\section{Comprometimento com a entrega}

Esta categoria trata do empenho dos grupos de trabalho para atender às demandas relativas aos ciclos orçamentários de forma colaborativa. Os entrevistados entendem que os grupos de trabalho se comprometem com as demandas nos ciclos orçamentários anuais e/ou nas revisões posteriores e as cumprem, ainda que esforços adicionais sejam exigidos. Esse comprometimento, "[...] uma força que liga os indivíduos ao rumo de ações relevantes para um objetivo" (MEYER e HERSCOVITCH, 2001), é coletivo e compartilhado, de forma que o cumprimento das tarefas é visto como resultado da equipe e não de indivíduos isolados (NELSON e WINTER, 2005). A teoria acerca da articulação dinâmica entre as perspectivas ostensiva e performativa das rotinas (FELDMAN, 2000, 2003) auxilia no entendimento de que os grupos de trabalho precisam atuar e resolver as novas demandas originadas em atividades extras (performativo) e adequá-las aos requisitos institucionais (ostensivo). É comum notar esforços compartilhados no grupo, envolvendo noite/madrugadas e finais de semana a fim de atender os requisitos, conforme as entrevistas E30 e E11:

[...] parte de orçamento tem muito trabalho que a gente chama de ad hoc, são as coisas que surgem sem estarem planejadas, então análises que a gente tem que fazer pra entregar [E30].

[...] mudou tudo de um dia pro outro e o prazo para apresentação do conselho era no dia seguinte. Então tinha que entregar tudo no mesmo dia e a gente entrou oito horas da manhã e só foi sair meiodia do dia seguinte [E11].

Essa situação torna necessário o ajustamento das rotinas exigindo ações e iniciativas não previstas, fato que agrava a agenda de atividades que estava prevista para o grupo.

As dimensões explicativas associadas a essa categoria são, além do ajustamento entre os aspectos performativo e ostensivo, a natureza das relações, exprimindo a característica colaborativa entre os integrantes do grupo de trabalho: "todo mundo acaba se ajudando, porque a gente tem um objetivo em comum que é entregar o projeto" [E34]. Mesmo quando algum membro do grupo questiona sobre as tarefas extras, não se cogita a "não entrega": "Comprometimento, com certeza. A gente recebe prazos de top down. Você pode até questionar: tipo 'poxa, por que que isso precisa ser para amanhã? Isso não faz sentido', mas não passa pela nossa cabeça não entregar" [E22].

Essa postura acerca do comprometimento com as entregas ilustra o atributo "engajamento subjetivo" (RETOUR e KROHMER, 2011, p. 50), que pode fundamentar a competência coletiva.

Chama também a atenção trechos das entrevistas em que se revelam situações em que antigos membros desses grupos não se adequaram a essa forma de comprometimento e, por isso, em pouco tempo, mudaram de área ou de empresa. Como possíveis motivações para o comprometimento desses profissionais, os entrevistados mencionaram a flexibilidade dos horários 
de trabalho em períodos mais tranquilos, enquanto parece não haver vinculação com remuneração extra ou banco de horas formal, conforme observado, também, em Silva e Ruas (2016).

\section{Reconfiguração das rotinas}

Parece ser um princípio comum a esses grupos a perspectiva de que as rotinas precisam/podem ser "melhoradas e reconfiguradas" de forma continuada. Em outras palavras, os grupos parecem se colocar além da perspectiva ostensiva das rotinas, ou seja, parecem não se limitar a cumprir os requisitos institucionais das rotinas. Esse processo tem origem na própria iniciativa das equipes - percepção desses gestores, confirmada pelos membros das equipes, o que revela o aspecto performativo dessas rotinas (FELDMAN, 2000, 2003).

O entrevistado E30 alegou que esses “processos são construídos de baixo para cima", enquanto as entrevistas de E19, E20, E27, E35 ilustram impactos positivos nas agendas de atividades, uma vez que suas equipes têm conseguido, em conjunto e gradativamente, reduzir as jornadas excessivas: “E a cada ano a gente tem reduzido, sim, o número de horas extras [...] Já teve orçamentos da gente dormir aqui, ter que ficar até o dia seguinte ou a madrugada aqui, e hoje a gente não chega nesse nível mesmo" [E19]. Essas ações sugerem que o grupo exerce uma forma colaborativa de solucionar os problemas complexos do contexto e aprende pela prática (ODELIUS, ABBAD, RESENDE JUNIOR et al., 2011).

Uma dimensão explicativa relevante nesta categoria é a autonomia dos grupos. Compreende-se que há "agência" para a modificação das rotinas (GIDDENS, 1984; FELDMAN, 2000), em uma abordagem coletiva, conforme explicou o gestor E16: "Eles repetem no geral que é rotineiro, mas, assim, eles são analíticos o suficiente para criticar se alguma coisa pode ser melhorada. Então eles buscam, e eu também estimulo isso, de tentar o que a gente pode fazer para ganhar produtividade e fazer em menos tempo".

Assim sendo, as equipes tomam iniciativas compartilhadas e colaborativas para modificar/adaptar/recriar suas rotinas orçamentárias, e podem, além de reduzir os excessos nas jornadas de trabalho, alcançar resultados positivos de eficiência e qualidade. Conforme Arnoud e Falzon (2013) apontam, o desempenho superior de alguns grupos envolve a cooperação, comunicação e confiança mútua. Essa categoria evidencia a geração de novos padrões de ação, por motivação do próprio grupo no desempenho das rotinas, independentemente de influências externas. Exprime, assim, uma dinâmica interna desenvolvida por parte dos grupos (FELDMAN, 2016).

\section{Disponibilização compartilhada}

Essa categoria descritiva trata da disponibilidade dos indivíduos e coletivos para a auto-organização, a fim de atingir um melhor desempenho das rotinas, especialmente quando surgem situações imprevistas nos ciclos orçamentários. Além das atividades, são consideradas as responsabilidades de cada membro da equipe. Nesse processo, as equipes desenvolvem e compartilham a consciência sobre a interdependência das atividades e buscam formas para manter sua estrutura mais "fluida" por meio da prática de redundâncias - rodízios e backups - na qual os membros das equipes aprendem o trabalho uns com os outros. Essa flexibilidade estrutural nas equipes favorece a continuidade e a qualidade dos trabalhos e evita que as rotinas sofram rupturas provocadas por demandas extras ou problemas individuais dos membros das equipes. Dessa forma, esta categoria corrobora a menção de Le Boterf (2014) sobre "calçarem os sapatos dos outros" e pode ser identificada nos trechos das entrevistas:

[...] A gente começa a dar essa questão de substituição de férias, que eu acho que é a melhor forma de um começar a pegar o trabalho do outro. Criar backup é importantíssimo. Porque para cada atividade sempre tem que ter um backup. Porque não pode ter na equipe uma pessoa fazendo uma coisa que só ela saiba fazer [E20].

A gente, às vezes, tenta trocar esses lugares para adquirir uma multifuncionalidade no time. Hoje em dia, a gente já adquiriu uma certa experiência com os números e a gente já conseguiu reduzir bastante essa jornada durante o período de orçamento [E30].

A natureza colaborativa na prática dos backups foi também apontada pela entrevistada E19 como motivadora e uma alternativa para os treinamentos formais. Outras entrevistas também manifestaram um aspecto deliberativo de "solidariedade nas equipes": 
"acaba criando realmente uma relação mais próxima" [E24]; "todo mundo se ajuda porque tem muita pressão" [E20]. Ou seja, há uma consciência na equipe de que essa colaboração se torna indispensável porque os trabalhos são interdependentes:

Tem que ter uma sintonia muito grande, porque qualquer alteração que a pessoa de despesa fizer vai impactar, vai mexer em fluxo de caixa, capital de giro. [...]. Então se a equipe não estiver em sintonia, se eles não se falarem... É por isso que as coisas, às vezes, não batem. [...]. Eu gero consequência em alguém, e alguém também gera consequência em mim, então esse coletivo aqui funciona bem, a gente até na hora de fazer uma seleção, a gente tenta ver pessoas que tenham esse perfil [E19].

Embora predominante, essa condição não é absoluta, pois, entre os relatos, três respondentes afirmaram que não vivenciam as práticas de redundância nas empresas onde atuam, mas, mesmo assim, concordam em "teoria" com essa ideia ou já as vivenciaram em empresas anteriores. Já a entrevistada E18 trouxe uma visão diferente das demais. Em sua opinião, a "falta de confiança" mútua (medo que o outro faça melhor o trabalho) gera uma limitação para que as práticas de redundância e de auto-organização sejam adotadas:

Eu acho que as pessoas pensam muito "ah não vou passar pra ele o que eu faço porque ele vai fazer melhor do que eu e isso pode ser ruim para mim, posso ser mandado embora, podem me botar na geladeira [...] por exemplo: eu tenho uma pessoa que cuida só da parte de estoque, essa pessoa vive reclamando que está sobrecarregada [...]. Ele não faz isso [não pratica a redundância] porque ele sabe que tem toda a informação na mão dele [...]. Mas eu acho que acaba gerando uma competição velada. É uma competição para se proteger, com medo de ser substituído [E18].

Esse relato E18 posiciona a questão da "confiança na equipe" como um forte condicionante para a categoria Disponibilização Compartilhada, assim como confirma o argumento de Edmonson (1999, p. 375), segundo o qual a "construção da confiança no grupo de trabalho [trust] é um 'ingrediente' para criar um clima de segurança psicológica”, uma vez que esta pode representar uma crença compartilhada, por meio da qual os participantes de um grupo, tacitamente, sentem-se seguros para se expressar sem o receio de serem punidos ou rejeitados (EDMONSON, 1999). De fato, a confiança mútua, conforme se observa na entrevista E18 é também um elemento-chave na construção de CC (MICHAUX, 2011).

\section{Construção de redes de relacionamento}

A categoria Construção de Redes de Relacionamento refere-se especificamente à tentativa de compreender o ponto de vista das áreas adjacentes e áreas clientes. Diz respeito ao fato de que os gestores entendem que as equipes posicionam seu olhar para além das próprias rotinas e da própria equipe; concebem um "pertencer a uma organização" para a construção de relacionamentos facilitadores da troca de informações com outras áreas e, com isso, obtêm as melhorias na performance das rotinas que envolvem essas outras áreas. Essa disposição é explicada pela condição institucional das rotinas de orçamento; ao fazer parte de uma ecologia de rotinas organizacionais, as rotinas orçamentárias afetam e são afetadas por outras rotinas (FELDMAN, PENTLAND, D’ADDERIO et al., 2016).

É uma área que você tem muita interação com outras áreas da empresa. Então, assim, a gente demanda muito de outras áreas da empresa [...] você tem o orçamento corporativo [...] e [...] locais e que pegavam informação das áreas de negócio para poder fazer. A gente era um grande consolidador. Então, a gente criava, por exemplo, as planilhas que iam ser preenchidas, configurava o sistema para que as áreas pudessem colocar [...] a gente vai fazer desse jeito: "o que vocês concordam? O que vocês não concordam?" [E24] (grifo nosso).

Na dimensão de ajustamento entre os aspectos performativo e ostensivo, a observação das rotinas adjacentes expressa a atenção nas vantagens mútuas relacionadas às iniciativas tanto de modificação, quanto de melhoria das rotinas. Em paralelo, a natureza das relações intergrupos permanece colaborativa, enfatizada pela inexistência de conflitos entre indivíduos de diferentes rotinas. Os membros das equipes reconhecem as opiniões dos gestores e reforçam a existência de autonomia para que a relação com as pessoas das outras áreas se viabilize, muitas vezes em níveis hierárquicos superiores: "Eu chegava direto e marcava reunião com o diretor [de outra área] para apresentar o número, para rever, com o gerente [...] você acaba tendo acesso livre aos diretores e, principalmente, nessa fase" [E37]. É possível observar que essa interação de agentes em 
múltiplas rotinas pode reforçar a noção do próprio grupo em lidar com situações a serem superadas em uma visão processual, em fluxo (CERRETTO e DOMENICO, 2016).

O impacto positivo e mútuo entre rotinas distintas, propiciado pela rede de relacionamentos, pode ser observado a seguir:

Por exemplo, a gente mudou nosso sistema [processo] de controle de investimentos. [...] ano passado [...] falou "não, não tá funcionando nem pra gente, nem pro Marketing, vamos construir um novo, mas vamos construir junto". Então a gente fez, e tentou ouvir o que eles achavam que podia melhorar. Obviamente que a gente podia ter feito [sozinhos][...], mas não, a gente tentou ouvir o que eles achavam [E23].

A combinação entre categorias descritivas e dimensões explicativas caracteriza e esclarece o mapa teórico da consciência coletiva, construída com base na análise das informações obtidas com gestores e membros dos grupos de trabalho atuantes em rotinas orçamentárias. No contexto complexo das rotinas de orçamento empresarial, onde se configuram urgências e envolvimento de diversas áreas da organização, as categorias descritivas resultantes da fenomenografia podem ser consideradas adequadas ao que defende, predominantemente, a literatura sobre competências coletivas, especialmente no que se refere à transcendência das equipes em relação às competências individuais (RETOUR e KROHMER, 2011) e ao alcance de um nível de performance superior à soma das competências individuais (LE BOTERF, 2014).

\section{CONSIDERAÇÕES FINAIS}

Este estudo objetivou identificar processos formadores de competências coletivas em grupos de trabalho atuantes em rotinas orçamentárias. Para tanto, empreendeu-se uma pesquisa qualitativa que contemplou a percepção de gestores dessas rotinas em diferentes empresas ( 1 a etapa) e, em seguida, a percepção de participantes de grupos de trabalho que as realizam ( 2 a etapa). Os resultados da pesquisa destacam contribuições ao debate acadêmico e à atuação gerencial, no ambiente organizacional.

Primeiramente, nota-se que o emprego da noção de RO como referência analítica viabilizou o exame dos principais processos da elaboração de orçamentos corporativos, com ênfase na dinâmica da recursividade entre seus aspectos ostensivo e performativo e na predominância da configuração coletiva em relação às iniciativas individuais (FELDMAN, 2003). Confirmou-se, portanto, que a teoria sobre RO, à qual têm sido acrescidas novas e importantes contribuições teóricas e empíricas, parece apresentar, atualmente, um amplo potencial para ser empregada como referência analítica em processos corporativos importantes, tanto em uma perspectiva acadêmica - como, por exemplo, na identificação das formas de recursividade entre aspectos ostensivos e performativos de processos organizacionais -, quanto gerencial - alternativas de gestão para o caso de coletivos de trabalho, temas desenvolvidos neste trabalho.

Segundo, a categoria explicativa Reconfiguração das Rotinas, que destaca as iniciativas nos grupos visando a melhorias em seus desempenhos, constitui um exemplo expressivo de que as RO podem abrigar e mobilizar atributos e competências de natureza coletiva. A recorrência no tempo dessas adaptações - entre as mudanças propostas nas iniciativas de melhoria e a estabilidade - vai exigir ajustamentos na atuação dos participantes, na forma de mais interdependência entre os participantes dos grupos, bem como na formação de atributos/competências de natureza coletiva, do tipo colaboração mútua, compartilhamento de habilidades e conhecimentos, comprometimento com a entrega, etc. (RETOUR e KHROMER, 2011). Nessa condição, o processo que dá origem à categoria explicativa Reconfiguração das Rotinas pode resultar no desenvolvimento de competências de natureza coletiva, tais como a capacidade de adaptação às mudanças ou o compartilhamento de responsabilidades no grupo.

Terceiro, o encaminhamento da pesquisa e seus resultados valorizaram os processos formadores de atributos e competências de natureza coletiva em rotinas orçamentárias. Entendendo que esses atributos e competências podem apresentar diferentes configurações e naturezas de acordo com os ambientes onde são construídos, com as características e trajetórias das organizações onde se formam, podem tornar-se dificilmente replicáveis em outros ambientes. Ou seja, são específicos à organização e ao ambiente onde são gerados. Por sua vez, os processos de formação de CC podem ser adaptados às condições de outras organizações, desde que intermediados pela noção de RO, conforme se observa neste trabalho. É o caso, por exemplo, da apropriação do processo de ajustamento e reconfiguração das rotinas, como forma de identificar a formação de atributos do tipo colaboração, confiança mútua, comprometimento, por meio dos quais se constituem as CC. Assim, a sistematização de 
processos capazes de formar e desenvolver atributos e competências em coletivos de trabalho parece ser um conhecimento relevante para gestores de rotinas corporativas em geral, bem como para profissionais seniores em gestão de pessoas.

Ademais, destaca-se como contribuição deste trabalho a aplicação do método da fenomenografia - uma abordagem teóricometodológica oriunda da área de Educação - no campo dos Estudos Organizacionais. Assim, as concepções identificadas por meio de variadas experiências profissionais em torno de um determinado fenômeno podem ser recompostas, em largo espectro, no contexto organizacional. Além disso, há de se considerar que se evidenciou a aplicabilidade prática do Mapa de Espaço de Resultado, por meio da sistematização das concepções/categorias, no contexto organizacional. Enfim, a fenomenografia permite a captura da dinâmica investigada e o entendimento de que as categorias são concepções dos sujeitos entrevistados acerca do fenômeno.

Cabe ressaltar a baixa frequência de trabalhos examinando a questão das CC em ambiente de RO. Certamente, a disponibilidade de outros trabalhos sobre o tema permitiria a ampliação e o aprofundamento das análises aqui desenvolvidas. Trata-se de uma limitação considerável para esta investigação. Por isso mesmo, a sugestão para novas pesquisas empíricas passa pela replicação da abordagem aqui realizada, tratando da construção de CC em outros tipos de RO. 


\section{REFERÊNCIAS}

AKERLIND, G. S. Variation and commonality in phenomenographic research methods. Higher Education Research \& Development, v. 24, n. 4, p. 321-334, nov. 2005.

ALBA, D. D.; TSOUKAS, H. Understanding the (re)creation of routines from within: a symbolic interactionist perspective. Academy of Management Review, v. 38, n. 2, p. 181-205, 2013.

ARNAUD, N.; MILLS, C. E. Understanding interorganizational agency: a communication perspective. Group \& Organization Management, v. 37, n. 4, p. 452-485, 2012.

ARNOUD, J.; FALZON, P. Changement organisationnel et reconception de l'organisation: des ressources aux capabilités. Activités, v. 10, n. 2, p. 109-113, 2013.

BOREHAM, N. A theory of collective competence: challenging the neo-liberal individualisation of performance at work. British Journal of Educational Studies, v. 52, n. 1, p. 5-17, mar. 2004.

BOREHAM, N. Competence as collective process. In: CATTS, R.; FALK, I.; WALACE, R. (Eds.). Vocational learning: innovative theory and practice. Dordrecht: Springer, 2011. p. 77-91. 14v.

CAROLY, S.; BARCELLINI, F. Le développement de l'activité collective. In: FALZON, P. Ergonomie Constructive. France: PUF, 2013. Disponível em: <https://hal.archives-ouvertes.fr/halshs-00860638/document>. Acesso em: 08 set. 2017.

CERRETTO, C.; DOMENICO, S. M. R. Mudança e Teoria Ator-Rede: humanos e não humanos em controvérsias na implementação de um centro de serviços compartilhados. Cadernos EBAPE.BR, Rio de Janeiro, v. 14, n. 1, p. 83-115, 2016.

COLLIER-REED, B.; INGERMAN, Å. Phenomenography: from critical aspects to knowledge claim. In: HUISMAN, J.; TIGHT, M. (Ed.). Theory and method in higher education research. Emerald Group, 2013. p. 243-260. (International Perspectives on Higher Education Research, v. 9).

CYERT, R. M., MARCH, J. G. A behavioral theory of the firm. PrenticeHall: New Jersey, 1963.

DEFÉLIX, C. et al. La compétence collective dans le contexte de la globalisation du management: retrouver le lien avec la performance. @ GRH, n. 2, p. 31-50, 2014.

EDMONSON, A. Psychological safety and learning behavior in work teams. Administrative Science Quarterly, n. 2, p. 350-383, 1999.

EKHOLM, B.; WALLIN, J. The impact of uncertainty and strategy on the perceived usefulness of fixed and flexible budgets. Journal of Business Finance \& Accounting, v. 38, n. 1-2, p. 145-164, jan./mar. 2011.

FELDMAN, M. S. Routines as process: past, present, and future. In: HOWARD-GRENVILLE, J. et al. Organizational Routines: how they are created, maintained, and changed. UK: Oxford University Press, 2016. p. 23-46.

FELDMAN, M. S. A performative perspective on stability and change in organizational routines. Industrial and Corporate Change, v. 12, n. 4, p. 727-752, 2003.

FELDMAN, M. S. Organizational routines as a source of continuous change. Organization Science, v. 11, n. 6, p. 611-629, 2000.
FELDMAN, M. S. et.al. Beyond routines as things: introduction to the special issue on routine dynamics. Organization Science, v. 27, n. 3, p. 505-513, maio/jun. 2016.

FELDMAN, M. S; PENTLAND, B. T. Reconceptualizing organizational routines as a source of flexibility and change. Administrative Science Quarterly, v. 48, n. 1, p. 94-118, 2003.

GHAURI, P. Designing and conducting case studies in international business research. In: MARSCHAN-PIEKKARI, R.; WELCH, C. Handbook of qualitative research methods for international business. Cheltenham: Edward Elgar, 2004.

GIDDENS, A. A constituição da sociedade. 2. ed. São Paulo: Martins Fontes, 1984.

KIHN, L. How do controllers and managers interpret budget targets? Journal of Accounting \& Organizational Change, v. 7, n. 3, p. 212 236, 2011.

LE BOTERF, G. Construire les compétences individuelles et collectives: le modèle: agir avec compétence en situation - Les réponses à plus de 100 questions. Paris: Editions Eyrolles, 2014.

LE BOTERF, G. Desenvolvendo a competência dos profissionais. Porto Alegre: Artmed, 2003.

LEPLAT, J. Compétences individuelles, compétences collectives. Psychologie du Travail et des Organisations, v. 6, n. 3-4, p. 47-73, 2000.

LOUFRANI-FEDIDA, S.; MISSONIER, S. The project manager cannot be a hero anymore! Understanding critical competencies in project-based organizations from a multilevel approach. International Journal of Project Management, v. 33, n. 6, p. 1220-1235, 2015.

MARCH, J. G.; SIMON, H. A. Organizations. New York: Wiley, 1958.

MACKE, J.; CRESPI, K.M. "One swallow does not make a summer": the development of an instrument for measuring collective competences in information technology teams. SAGE Open, p. 1-11, abr./jun. 2016.

MARTON, F.; BOOTH, S. A. Learning and awareness. Mahwah: Lawrence Erlbaum, 1997.

MARTON, F. Phenomenography: describing conceptions of the world around us. Instructional Science, v. 10, n. 2, p. 177-200, 1981.

MERCHANT, K. A. Modern management control systems: text and cases. London: Prentice Hall, 1998.

MERCHANT, K. A. The design of the corporate budgeting system: influences on managerial behavior and performance. The Accounting Review, v. 56, n. 4, p. 813-829, 1981. Disponível em: <http://www. jstor.org/stable/247203>. Acesso em: 11 jan. 2018.

MEYER, J. P.; HERSCOVITCH, L. Commitment in the workplace: toward a general model. Human Resource Management Review, v. 11, n. 3, p. 299-326, 2001.

MICHAUX, V. Articular as competências individual, coletiva, organizacional e estratégica: esclarecendo a teoria dos recursos e do capital social. In: RETOUR, D. et al. (Org.). Competências coletivas: no limiar da estratégia. Porto Alegre: Bookman, 2011. p. 1-21. 
NASCIMENTO, C. A. X.; RUAS, R. L; SILVA, D. Rotinas Organizacionais no Ambiente da Teoria Evolucionária. Revista Ibero-Americana de Estratégia - RIAE, v. 16, n. 3, jul./set., 2017.

NELSON, R. R.; WINTER, S. G. Uma Teoria Evolucionária da Mudança Econômica. Campinas: Unicamp, 2005. (Traduzida da obra original-1982).

ODELIUS, C. C. et al. Processos de aprendizagem, competências aprendidas, funcionamento, compartilhamento e armazenagem de conhecimentos em grupos de pesquisa. Cadernos EBAPE.BR, Rio de Janeiro, v. 9, n. 1, p. 199-220, 2011.

PARMIGIANI, A.; HOWARD-GRENVILLE, J. Routines revisited: exploring the capabilities and practice perspectives. The Academy of Management Annals, v. 5, n. 1, p. 413-453, 2011.

PENTLAND, B. T.; FELDMAN, M. S. Organizational routines as a unit of analysis. Industrial and corporate change, v. 14, n. 5, p. 793-815, 2005.

RETOUR, D.; KROHMER, C. A competência coletiva: uma relaçãochave na gestão das competências. In: RETOUR, D. et al. (Org.).
Competências coletivas: no limiar da estratégia. Porto Alegre: Bookman, 2011. p. 45-78.

RUAS, R. et al. Competências coletivas: resultados teórico-práticos acerca de sua configuração em empresas brasileiras. In: ENCONTRO DA ASSOCIAÇÃO NACIONAL DE PÓS-GRADUAÇÃO E PESQUISA EM ADMINISTRAÇÃO, 32., 2013, Rio de Janeiro. Anais... Rio de Janeiro: EnANPAD, 2013.

SANDBERG, J. Understanding human competence at work: an interpretative approach. Academy of Management Journal, v. 43, n. 1, p. 9-25, 2000.

SILVA, F. M. O que sabemos sobre competências coletivas? In: ENCONTRO DA ASSOCIAÇÃO NACIONAL DE PÓS-GRADUAÇÃO E PESQUISA EM ADMINISTRAÇÃO, 36., 2012, Rio de Janeiro. Anais... Rio de Janeiro: EnANPAD, 2012.

SILVA, F. M.; RUAS, R. L. Competências Coletivas: Considerações acerca de sua formação e desenvolvimento. REAd. Revista Eletrônica de Administração, Porto Alegre, v. 22, n. 1, p. 252-278, 2016.

Samantha Luiza de Souza Broman

ORCID: https://orcid.org/0000-0001-5239-8629

Doutoranda e mestre em Administração de Empresas pela Pontifícia Universidade Católica do Rio de Janeiro (IAG/PUC- Rio); Professora colaboradora na Universidade Federal do Rio de Janeiro (UFRJ), Rio de Janeiro - RJ, Brasil. E-mail: sambroman@ @otmail.com

Roberto Lima Ruas

ORCID: https://orcid.org/0000-0002-2901-6378

Doutor em Economia pela Université Jules Verne, França; Mestre em Economia pela Université Paris I-Sorbonne, França; Professor do Programa de Pós-Graduação em Administração da Universidade Nove de Julho (UNINOVE), São Paulo - SP, Brasil. E-mail: roberuas@gmail.com

Sandra Regina da Rocha-Pinto

ORCID: https://orcid.org/0000-0002-5121-4231

Doutora em Educação e Mestre em Administração de Empresas pela Pontifícia Universidade Católica do Rio de Janeiro (IAG/PUC- Rio); Professora do Departamento de Administração de Empresas (IAG/PUC-Rio), Rio de Janeiro - RJ, Brasil. E-mail: sanpin@iag.puc-rio.br 